\title{
A numerical model and validation of phase change material integrated thermoelectric radiant cooling panel
}

\author{
Hansol Lim, Hye-Jin Cho, Seong-Yong Cheon, Soo-Jin Lee, and Jae-Weon Jeong* \\ Department of Architectural Engineering, Hanyang University, Republic of Korea
}

\begin{abstract}
A phase change material based radiant cooling panel with thermoelectric module (PCM-TERCP) is proposed in this study. It consists of two aluminium panels, and phase change materials (PCMs) sandwiched between the two panels. Thermoelectric modules (TEMs) are attached to one of the aluminium panels, and heat sinks are attached to the top side of TEMs. PCM-TERCP is a thermal energy storage concept equipment, in which TEMs freeze the PCM during the night whose melting temperature is $16^{\circ} \mathrm{C}$. Therefore, the radiant cooling panel can maintain a surface temperature of $16^{\circ} \mathrm{C}$ without the operation of TEM during the day. Furthermore, it is necessary to design the PCM-TERCP in a way that it can maintain the panel surface temperature during the targeted operating time. Therefore, the numerical model was developed using finite difference method to evaluate the thermal behaviour of PCM-TERCP. Experiments were also conducted to validate the performance of the developed model. Using the developed model, the possible operation time was investigated to determine the overall heat transfer coefficient required between radiant cooling panel and TEM. Consequently, the results showed that a overall heat transfer coefficient of $394 \mathrm{~W} / \mathrm{m}^{2} \mathrm{~K}$ is required to maintain the surface temperature between $16^{\circ} \mathrm{C}$ to $18^{\circ} \mathrm{C}$ for a 3 hours operation.
\end{abstract}

\section{Introduction}

Thermoelectric module (TEM) has attracted an increasing attention owing to its many advantages such as fast response and compact size without refrigerant, moving parts, noise and vibration [1]. Recently, many applications of TEM using heating, ventilation and air conditioning (HVAC) have been studied. Among many systems, the thermoelectric radiant cooling panel (TERCP) showed good feasibility [2-4].

However, it was difficult to save energy due to the low coefficient of performance (COP) of TEM [5]. In general, TEM can get higher $\mathrm{COP}$ when the temperature difference of cold and hot sides is small $[6,7]$. It means that if the air or water temperature required for removing the rejected heat from the hot side of TEM is lower, TERCP can show higher COP during cooling operation.

Therefore, integration of phase change material (PCM) with TERCP has been proposed, to operate the TERCP during night using colder outdoor air. During the off-peak time at night, TERCP freezes the PCM, so that the PCM integrated TERCP (PCM-TERCP) can maintain the radiant cooling surface temperature during the HVAC operation time without energy consumption. This system can reduce the operational energy and operate the system during off-peak time. Accordingly, a proper design of PCM-TERCP is required.

In this study, a numerical model of PCM-TERCP was developed and validated using mock up model of PCMTERCP. Using the developed model, the design process of PCM-TERCP was established.

\section{System descriptions}

PCM-TERCP is a parallel cooling unit that can handle sensible cooling load and is installed on the ceiling in a conditioned zone. It consists of TEM, heat sinks, insulation, PCM, and its storage box (Fig. 1). It is a combination of an air-cooled type TERCP and PCM. During the off-peak time at night, the TERCP operates and freezes the PCM in a storage box. The melting temperature of $\mathrm{PCM}$ can be set as $16^{\circ} \mathrm{C}$ which is the general radiant cooling surface temperature. The solidified PCM can maintain the surface temperature until it changes its phase to liquid state during the HVAC operation time.

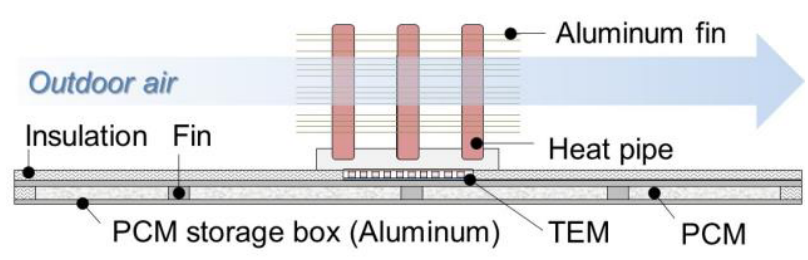

Fig. 1. Conceptual diagram of PCM-TERCP

To increase the operation time of PCM-TERCP without increase in energy consumption, it is important to properly design the heat exchange structure in the PCM storage box. Melting starts at the bottom boundary by heat convection and radiation from the conditioned zone, and the surface temperature increases rapidly after the bottom

\footnotetext{
* Corresponding author: jjwarc@hanyang.ac.kr
} 
boundary of PCM is liquefied. Therefore, the distribution of heat into the PCM storage box is important. The heat conductivity of PCM is low. However, there are many chemical and physical methods to increase it. The physical method of using fins in the PCM storage box was selected for this study.

\section{Model descriptions}

The numerical model of PCM-TERCP was developed for the situation after freezing, as the purpose of this model is investigation of possible operation time according to the structure of the PCM storage box. Finite difference method was used for the study and two-dimensional temperature of PCM-TERCP was analysed in section.

\subsection{Phase change material}

The property of PCM can be defined using specific heat based on its temperature from the previous study [4]. The concept of maximum value of equivalent specific heat $\left(C_{P C M, \max }\right)$ defined in Eq. (1) and the temperature range of the phase change $\left(2 \triangle T_{P C M}\right)$ were used.

$$
C_{P C M, \max }=\frac{Q_{P C M}}{\Delta T_{P C M}}-\frac{C_{P C M, S}+C_{P C M, l}}{2}
$$

The specific heat capacity $\left(C_{P C M}\right)$ as a function of temperature $\left(T_{P C M}\right)$ is as shown in Table 1 . In addition, an organic type PCM was selected owing to its stable characteristics and the property of PCM is summarized in Table 2.

Table 1. Specific heat capacity of PCM [8].

\begin{tabular}{|c|c|}
\hline$C_{P C M}$ & Temperature range of PCM \\
\hline \hline$C_{P C M, S}$ & if $T_{P C M} \leq T_{\text {melt }}-\Delta T_{P C M}$ \\
\hline$\frac{C_{P C M, \text { max }}-C_{P C M, S}}{\Delta T_{P C M}}\left(T_{P C M}-\right.$ & if $T_{\text {melt }}-\Delta T_{P C M}<T_{P C M} \leq$ \\
$\left.T_{\text {melt }}+\Delta T_{P C M}\right)+C_{P C M, S}$ & $T_{\text {melt }}$ \\
\hline$\frac{C_{P C M, l}-C_{P C M, \text { max }}}{\Delta T_{P C M}}\left(T_{P C M}\right.$ & if $T_{\text {melt }}<T_{P C M}<T_{\text {melt }}+$ \\
$\left.-T_{\text {melt }}-\Delta T_{P C M}\right)+C_{P C M, l}$ & $\Delta T_{P C M}$ \\
\hline$C_{P C M, l}$ & if $T_{P C M} \geq T_{\text {melt }}+\Delta T_{P C M}$ \\
\hline
\end{tabular}

Table 2. Properties of PCM used in this study.

\begin{tabular}{|c|c|}
\hline Description & Value \\
\hline Chemical name & "n-Hexadecane \\
\hline Melting temperature $\left[{ }^{\circ} \mathrm{C}\right]$ & $16\left(T_{\text {melt }}\right)$ \\
\hline $\begin{array}{l}\text { Tmperature range of the } \\
\text { phase change }\left[{ }^{\circ} \mathrm{C}\right]\end{array}$ & $1.0\left(2 \Delta T_{P C M}\right)$ \\
\hline Latent heat capacity $[\mathrm{kJ} / \mathrm{kg}]$ & $200\left(Q_{P C M}\right)$ \\
\hline $\begin{array}{l}\text { Specific heat capacity } \\
{\left[\mathrm{kJ} / \mathrm{kg} \cdot{ }^{\circ} \mathrm{C}\right]}\end{array}$ & $\begin{array}{l}C_{P C M, S}: 1800 \text { (Solid) } \\
C_{P C M, l}: 2250 \text { (Liquid) }\end{array}$ \\
\hline Density $\left[\mathrm{g} / \mathrm{cm}^{3}\right]$ & $\begin{array}{c}0.88 \text { (Solid at } 15^{\circ} \mathrm{C} \text { ) } \\
0.77 \text { (Liquid at } 25^{\circ} \mathrm{C} \text { ) }\end{array}$ \\
\hline Heat conductivity $[\mathrm{W} / \mathrm{m} \cdot \mathrm{K}]$ & $\begin{array}{c}0.15 \text { (Solid) } \\
0.20 \text { (Liquid) }\end{array}$ \\
\hline Volume expansion [\%] & 12.5 \\
\hline
\end{tabular}

\subsection{Convection and radiation coefficient}

Heat transfer from the surface of the radiant cooling panel to the room is by heat convection and radiation which are calculated by using Eqs. (2) - (8) [2,9-11]. The Reynolds number $(R e)$ of air below the radiant panel can be derived using the density of air $\left(\rho_{\text {air }}\right)$, velocity of air $\left(\nu_{\text {air }}\right)$, characteristic length of air $\left(L_{c}\right)$ and viscosity $(\mu)$ using Eq. (2). The characteristic length $\left(L_{c}\right)$ can be defined as the length of panel $\left(L_{\text {panel }}\right)$ when external fluid is considered. In addition, its Nusselt number $(\mathrm{Nu})$ is calculated using Reynolds number $(R e)$ and Prandtl number $(P r)$ of air (Eq. (3)). If there is no forced convection, the Grashof number (Gr) should be considered in Eq. (4) based on the acceleration due to gravity $(g)$ and the coefficient of cubical expansion of air $(\beta)$. Then, the Rayleigh number $(R a)$ is calculated (Eq. (5)) and the Nusselt number $(\mathrm{Nu})$ in natural convection condition is derived using Eq. (6). Finally, the heat convection coefficient at the surface of radiant panel is determined in Eq. (7).

$$
\begin{aligned}
& R e=\frac{\rho_{a i r} v_{a i r} L_{c}}{\mu} \\
& N u=\begin{array}{l}
0.664 \operatorname{Re}^{\frac{1}{2}} \operatorname{Pr}^{\frac{1}{3}}\left(\operatorname{Re}<5 \times 10^{5}\right) \\
0.037 \operatorname{Re}^{\frac{4}{5}} \operatorname{Pr}^{\frac{1}{3}}\left(\operatorname{Re} \geq 5 \times 10^{5}\right)
\end{array} \\
& G r=\frac{g \beta\left(T_{\text {surf }}-T_{\text {room }}\right) L_{c}{ }^{3}}{v_{\text {air }}{ }^{2}} \\
& R a=G r \times P r \\
& N u=0.27 R a^{1 / 4} \quad\left(10^{5}<R a<10^{11}\right) \\
& h_{\text {conv }}=\frac{\kappa_{\text {air }} N u}{L_{c}}
\end{aligned}
$$

The heat radiation coefficient can be defined using the emissivity of radiant panel $(\varepsilon)$, Stefan-boltzman coefficient $(\sigma)$, the mean radiant temperature of room $\left(T_{M R T}\right)$, and the surface temperature of panel $\left(T_{\text {surf }}\right)$ in Eq. (8) $[11]$.

$$
h_{\text {rad }}=\varepsilon \sigma\left(T_{M R T}^{2}+T_{\text {surf }}^{2}\right)\left(T_{M R T}+T_{\text {surf }}\right)
$$

Therefore, the cooling capacity of panel according to the surface temperature of radiant panel can be derived from Eq. (9) based on the assumption that the mean radiant temperature $\left(T_{M R T}\right)$ is equal to the room temperature $\left(T_{\text {room }}\right)$.

$$
Q_{\text {panel }}=\left(h_{\text {conv }}+h_{\text {rad }}\right) A_{\text {panel }}\left(T_{\text {room }}-T_{\text {surf }}\right)
$$

\subsection{Finite difference model}

Analysis of PCM-TERCP was conducted on an aluminium PCM storage box which consists of three parts: top aluminium panel, PCM, and bottom aluminium panel. The two-dimensional model was developed in cross- 
sectional direction using MATLAB. In addition, only half the area between the two TEMs was considered for analysis, to reduce the calculation time using symmetric boundary condition.

At the boundary contact with insulation and heat sinks, there was a heat transfer to air in the duct. Therefore, the overall thermal resistance between top aluminium panel and air in the duct was considered. Moreover, the air temperature in the duct was assumed to be room temperature.

\section{Validation experiments}

\subsection{Mock up model}

The mock up model of PCM-TERCP was designed and constructed for the purpose of the experiments. The 3D model and constructed model are shown in Fig. 2. The length and width of radiant panel were $0.4 \mathrm{~m}$ and three TEMs with heat sinks were used. It has the same crosssectional structure as shown in Fig. 1, however PCM pouch was used instead of PCM storage box to prevent the leakage problem. The pouch and the panels were made of aluminium for high heat conductivity. The thickness of PCM pouch, top, and bottom aluminium panel are $10 \mathrm{~mm}$, $5 \mathrm{~mm}$, and $3 \mathrm{~mm}$, respectively.

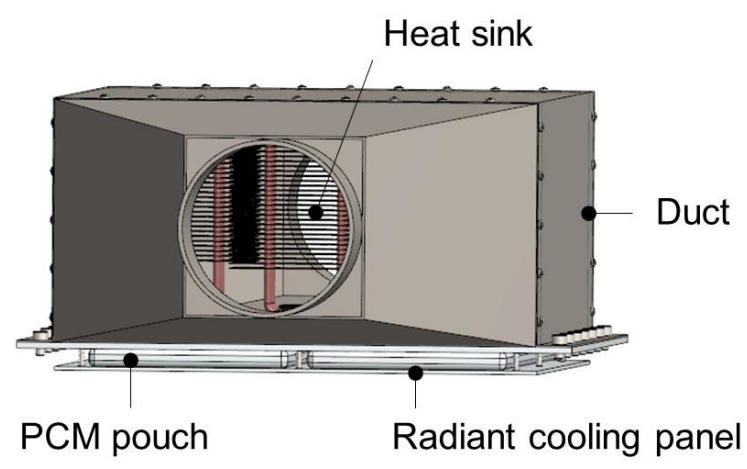

(a) 3D model of PCM-TERCP

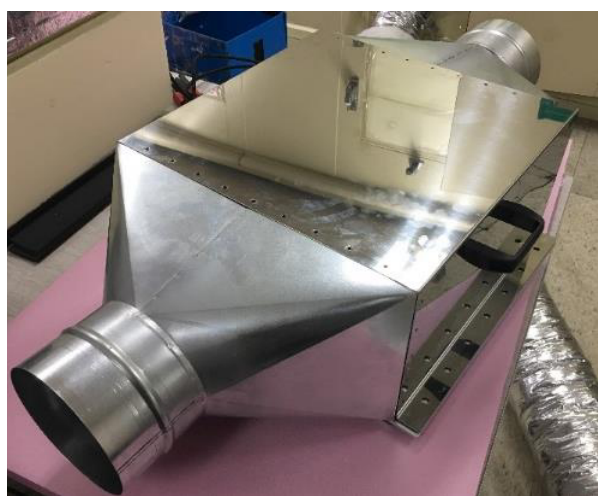

(b) Mock up model of PCM-TERCP

Fig. 2. 3D model and mock up model of PCM-TERCP

\subsection{Experimental set-up}

For experiments, the PCM had to be solidified using a aircooled type TERCP first. In this study, we consider only the performance and thermal behaviour of PCM-TERCP after freezing (i.e. passive cooling by PCM), therefore detailed operation process TERCP has not been described. After freezing the PCM, temperature at four points were measured as shown in Fig. 3a. Point 1 is below the aluminium panel where TEM is attached and point 2 and 4 were at the top and bottom sides of the PCM pouch, respectively. Surface temperature of the radiant panel is obtained from point 4 . The temperatures were measured using T-type thermocouples and data logger as shown in Fig. 3b. The data was recorded for 225 minutes at 1 minute intervals. Furthermore, the room temperature was constant at $24^{\circ} \mathrm{C}$.

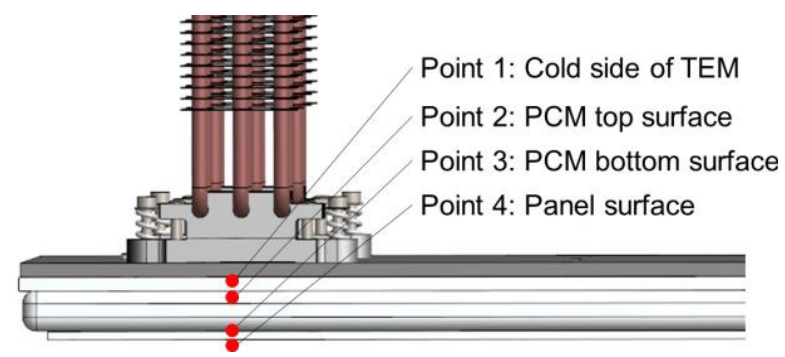

(a) Measurement points

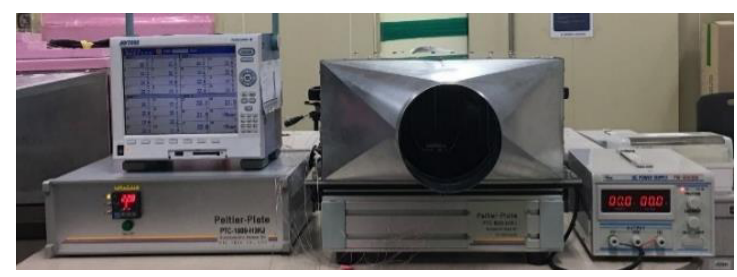

(b) Experiment equipment

Fig. 3. Experiment set-up for validation experiments.

\subsection{Validation results}

The measured and simulated temperatures at the four points during 225 minutes are compared and results are shown in Fig. 4. In the experiment, the PCM was cooled up to $10^{\circ} \mathrm{C}$, allowing for solidification and the measurement was started when temperature at point 2 reached $14^{\circ} \mathrm{C}$. In the simulation, the initial temperature was set to be $14^{\circ} \mathrm{C}$ at all points. Therefore, initial temperature at points 1,3 , and 4 were relatively large. The overall accuracy of the numerical simulation was good, with a maximum temperature difference of $1.28^{\circ} \mathrm{C}$ and an average error rate of $1.88 \%$.

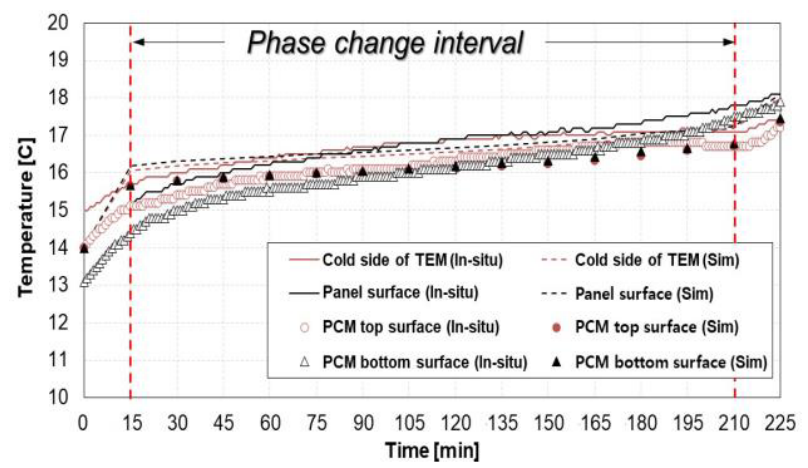

Fig. 4. Validation experiment results. 


\section{Design of the PCM storage box}

\subsection{Simulation cases}

Using a validated numerical model, the minimum overall heat transfer coefficient $(U)$ between the top and bottom panels was investigated in terms of the design conditions. The required design conditions were that, the maximum temperature of the bottom aluminium panel (i.e. radiant cooling panel) should maintain the temperature below $18^{\circ} \mathrm{C}$, at least for an hour when the room temperature and $\mathrm{T}_{\text {MRT }}$ were $28^{\circ} \mathrm{C}$ without air movements.

Overall heat transfer coefficient was selected because, if it is low, the PCM layer in contact with the bottom aluminium panel melts too fast to maintain the surface temperature for radiant cooling. Therefore, it is necessary to improve the overall heat transfer between the top and bottom panels using chemical or physical methods. Aluminium fins were selected for this study, to modify the overall heat transfer coefficient using fin numbers. The thickness of each fin was $5 \mathrm{~mm}$ and they were vertically placed between the top and bottom panels inside the PCM storage box and the interval between the fins was equal. The thicknesses of PCM storage box, insulation, top and bottom aluminium panels were $10 \mathrm{~mm}, 8 \mathrm{~mm}, 5 \mathrm{~mm}$, and $3 \mathrm{~mm}$, respectively. The schematic representation the of analysed cases are shown in Fig. 5.

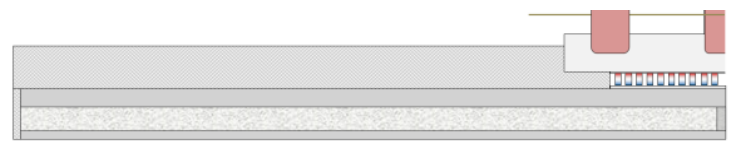

(a) 1 fin $\left(U=315 \mathrm{~W} / \mathrm{m}^{2} \cdot \mathrm{K}\right)$

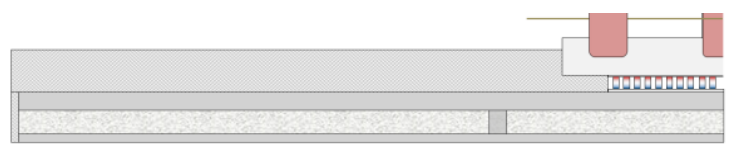

(b) 2 fins $\left(U=615 \mathrm{~W} / \mathrm{m}^{2} \cdot \mathrm{K}\right)$

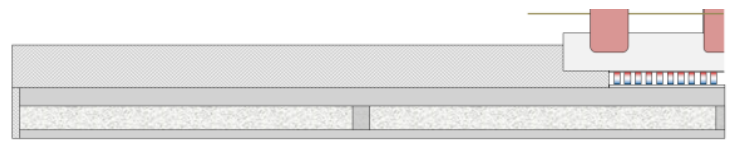

(c) 3 fins $\left(U=914 \mathrm{~W} / \mathrm{m}^{2} \cdot \mathrm{K}\right)$

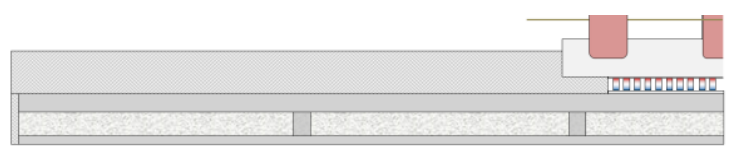

(d) 4 fins $\left(U=1,214 \mathrm{~W} / \mathrm{m}^{2} \cdot \mathrm{K}\right)$

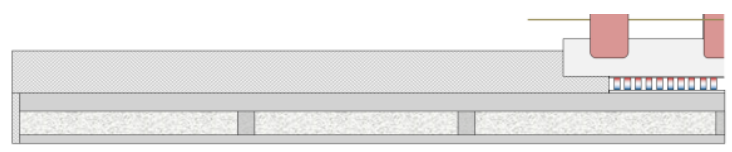

(e) 5 fins $\left(U=1,514 \mathrm{~W} / \mathrm{m}^{2} \cdot \mathrm{K}\right)$

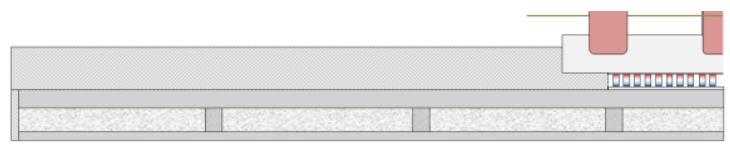

(f) 6 fins $\left(U=1,814 \mathrm{~W} / \mathrm{m}^{2} \cdot \mathrm{K}\right)$

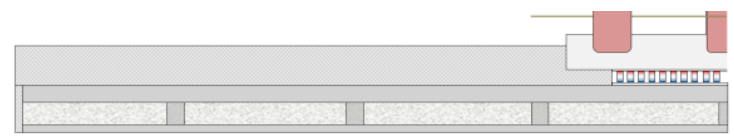

(g) 7 fins $\left(U=2,114 \mathrm{~W} / \mathrm{m}^{2} \cdot \mathrm{K}\right)$

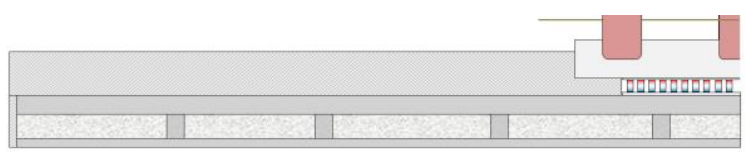

(h) 8 fins $\left(U=2,414 \mathrm{~W} / \mathrm{m}^{2} \cdot \mathrm{K}\right)$

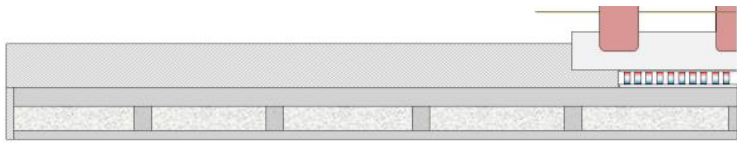

(i) 9 fins $\left(U=2,713 \mathrm{~W} / \mathrm{m}^{2} \cdot \mathrm{K}\right)$

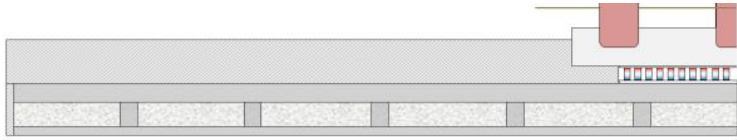

(j) 10 fins $\left(U=3,013 \mathrm{~W} / \mathrm{m}^{2} \cdot \mathrm{K}\right)$

Fig. 5. Simulation cases according to the number of heat fins inside the PCM storage box.

\subsection{Simulation results}

For all simulation cases, the initial temperature was $16^{\circ} \mathrm{C}$ and the temperature profiles after 1 hour, 2 hours and 3 hours during the melting process were simulated. As a comparative result, the temperature profiles of reference case (i.e. PCM-TERCP without fin), case (e) and case (j)as shown in Fig. 5 after 1 hour are shown in Fig. 6. The PCM-TERCP without fin showed the maximum surface temperature of $17.93^{\circ} \mathrm{C}$ at the bottom panel. In contrast, the PCM-TERCP with 5 and 10 fins showed those as $16.26^{\circ} \mathrm{C}$ and $16.16^{\circ} \mathrm{C}$, respectively. Therefore, it was proved that the heat fins can maintain the surface temperature of the radiant cooling panel. It means that the operating time for passive cooling can be increased by increasing the overall heat transfer coefficient between top and bottom panels.

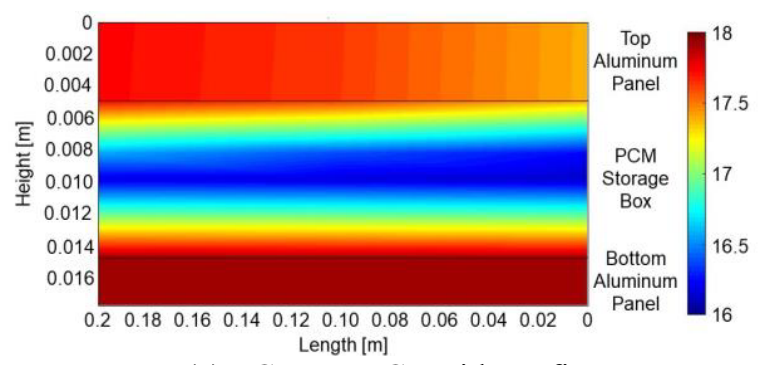

(a) PCM-TERCP without fin

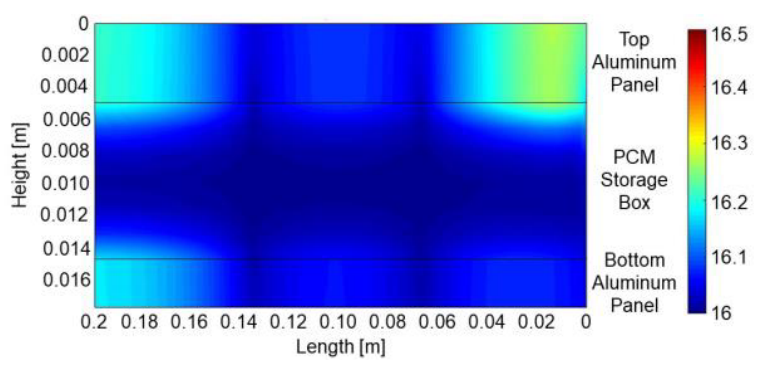

(b) PCM-TERCP with 5 fins 


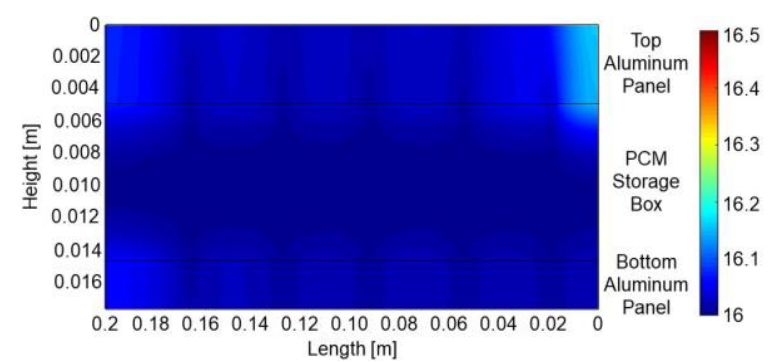

(b) PCM-TERCP with 10 fins

Fig. 6. Temperature profiles after 1 hour in melting process.

This is because, the high overall transfer coefficient can delay the melting of PCM at the boundary by distributing heat inside the PCM as shown in Fig. $6 \mathrm{~b}$ and c. This indicates that the latent heat of PCM can be used more evenly when the overall heat transfer coefficient is higher.

In Fig. 7, the relationship between the surface temperature for radiant cooling and the overall heat transfer coefficient between top and bottom aluminium panels is plotted, to determine the proper criteria in terms of the overall heat transfer coefficient. Surface temperature higher than $18^{\circ} \mathrm{C}$ is not suitable for radiant cooling and the minimum operating time of PCM-TERCP should be longer than $3 \mathrm{hrs}$. Hence, PCM-TERCP should have an overall heat transfer coefficient larger than at least $615 \mathrm{~W} / \mathrm{m}^{2} \cdot \mathrm{K}$ to satisfy the selected design conditions.

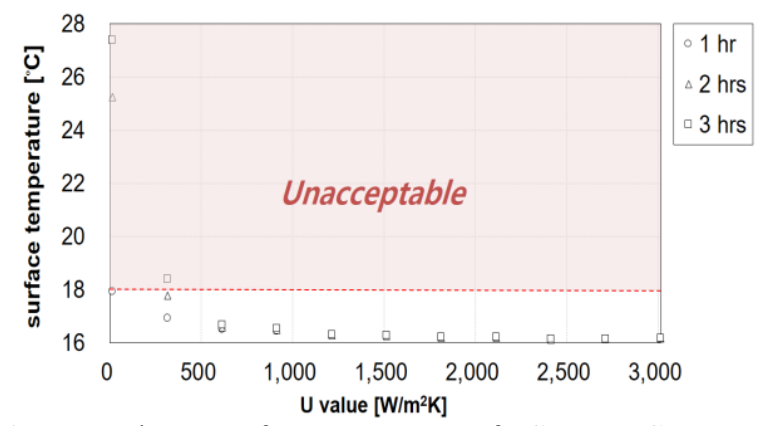

Fig. 7. Maximum surface temperature of PCM-TERCP according to the overall heat transfer coefficient $(U)$ of PCM storage.

\section{Conclusions}

In this study, a numerical model of PCM-TERCP was developed using finite difference method. The developed model was verified based on experiments. Using a numerical model, the appropriate overall heat transfer coefficient inside the PCM storage box was investigated, which is required to maintain the desired surface temperature of radiant panel. Further, the benefit of using heat fins to improve the overall heat transfer coefficient in a PCM storage box was studied and the minimum $U$ value required between top and bottom aluminium panels of PCM-TERCP was found to be $615 \mathrm{~W} / \mathrm{m}^{2} \cdot \mathrm{K}$.

However, it depends on the various design conditions such as the acceptable surface temperature for radiant cooling, operating time, room air temperature and initial temperature of PCM-TERCP in melting process. Therefore, future studies will include a more detailed analysis of PCM-TERCP using simulation and experiments, in order to determine the appropriate design guidelines.

This work was supported by the Korean Agency for Infrastructure Technology Advancement (KAIA) grants (19CTAP-C141826-02), and by the Korean Institute of Energy Technology Evaluation and Planning (KETEP) (No. 20184010201710).

\section{References}

1. D. Enescu, E. O. virjoghe, Renewable and Sustainable Energy Reviews 38, 903-916 (2014)

2. H. Lim, Y. K. Kang, J. W. Jeong, Appl. Therm. Eng. 144, 248-261 (2018)

3. Y. Luo, L. Zhang, Z. Liu, J. Wu, Y. Zhang, Z. Wu, Int. J. Heat Mass Transf. 114, 169-186 (2017)

4. L. Shen, Z. Tu, Q. Hu, C. Tao, H. Chen, Appl. Therm. Eng. 112, 688-697 (2017)

5. H. Lim, J. W. Jeong, Energy and Build. 169, 353-365 (2018)

6. H. Lim, J. W. Jeong, Appl. Therm. Eng. 136, 49-62 (2018)

7. H. S. Lee, John Wiley \& Sons Inc, Thermoelectric: Design and Materials (2017)

8. F. Goia, M. Perino, M. Haase, Energy and Build. 54, 141-153 (2012)

9. S. Ostrach, National Advisory Committee for Aeronautics, An Analysis of Laminar Freeconvection Flow and Heat Transfer about a Flat Plate Parallel to the Direction of the Generating Body Force (1953)

10. T. Fuji, H. Imura, Int. J. Heat Mass Transf. 1515, 755767 (1972)

11. Y. A. Cengel, McGraw-Hill, Heat and mass transfer: Fundamentals and applications (2007) 